\title{
Conciencia moral: ampliando su aplicación en salud. Aspectos teóricos y prácticos de los juicios de conciencia en Chile
}

\author{
Antonieta Valderrama Sandoval ${ }^{1}$, Rodrigo López Barreda ${ }^{2}$
}

Resumen: La conciencia se entiende habitualmente como un aspecto individual y subjetivo del ser humano; sin embargo, recientemente se ha destacado su carácter racional y sujeto a criterios externos de evaluación. La aplicación de los juicios de la conciencia moral es transversal a todos los campos de la atención en salud, incluso en la relación cotidiana con los pacientes.

La objeción de conciencia de los profesionales de la salud ha sido criticada porque podría faltar a la responsabilidad profesional; no obstante, seguir la conciencia recta es una obligación moral para todos, independiente del rol que se cumpla en un determinado momento. Impedir hacerlo es lesionar la autonomía e integridad moral de quien busca actuar en conciencia.

Palabras clave: conciencia, tareas morales, complicidad

\section{Moral conscience: widening its application in health. Theoretical and practical issues of moral judgment in Chile}

Abstract: Generally, conscience is understood as an individual and subjective character of human being; nevertheless, recently its rational character has been highlighted and subjected to external evaluation criteria. The application of moral conscience judgments is transversal to all health care fields, even in daily relations with patients.

Health care professionals conscience objection has been criticized because it could neglect professional responsibility; nevertheless, to follow an honest conscience is a moral duty for all, independently of role fulfilled in a certain moment. To prevent to do it means to damage autonomy and moral integrity of who seeks to act in conscience.

Key words: conscience, moral tasks, complicity

\section{Consciência moral: ampliando sua aplicação em saúde. Aspectos teóricos e práticos dos juízos de consciência no país}

Resumo: A consciência é entendida habitualmente como um aspecto individual e subjetivo do ser humano; entretanto, recentemente se tem destacado seu caráter racional e sujeito a critérios externos de avaliação. A aplicação dos juízos da consciência moral é transversal a todos os campos da atenção em saúde, inclusive na relação cotidiana com os pacientes.

A objeção de consciência dos profissionais de saúde tem sido criticada porque esta poderia faltar com a responsabilidade profissional; não obstante, seguir a consciência reta é uma obrigação moral para todos, independente do papel que se cumpra num determinado momento. Impedir fazê-lo é lesar a autonomia e a integridade moral de quem busca atuar com consciência.

Palavras-chave: consciência, tarefas morais, cumplicidade

\footnotetext{
${ }^{1}$ Interna de Medicina. Centro de Bioética, Facultad de Medicina, Pontificia Universidad Católica de Chile, Chile

${ }^{2}$ Instructor adjunto, Centro de Bioética, Facultad de Medicina, Pontificia Universidad Católica de Chile, Chile

Correspondencia: ralopez@puc.cl
} 


\section{Introducción y objetivos}

La objeción de conciencia en salud ha motivado recientemente múltiples publicaciones relacionadas con la definición de conciencia, sus juicios y la aplicación de estos a algunos casos paradigmáticos, tales como aborto, salud reproductiva, transfusión a Testigos de Jehová y los relativos al fin de la vida; sin embargo, se discute poco acerca del rol de la conciencia en lo cotidiano de la atención en salud, aspecto que ha sido olvidado en favor de temas más vigentes en la agenda pública.

El presente artículo busca responder a esta inquietud. Se discuten inicialmente los aspectos más relevantes del concepto de conciencia moral, enfatizando la relevancia de los juicios de conciencia y cómo estos se aplican en la práctica habitual. Posteriormente se discute el concepto de objeción de conciencia y se señalan algunos aspectos prácticos de la aplicación de los juicios de conciencia en el contexto nacional.

\section{La conciencia}

\section{La conciencia moral con una base objetiva}

Habitualmente se habla de conciencia interpretándola como una "voz interior" que nos diría qué está bien o cómo se debería actuar, sin mayor base que la subjetividad. Si bien actualmente no existe consenso respecto del concepto de conciencia(1), se ha destacado que la conciencia se fundamenta en una base objetiva, $\operatorname{racional}(2,3) \mathrm{y}$ que es, por tanto, susceptible de argumentación, lo que dista del concepto ampliamente difundido de conciencia subjetiva.

Siguiendo en la línea que destaca el rol de la racionalidad en la conciencia, Juan Pablo II, en su encíclica Veritatis Splendor, afirma que gracias a la razón distinguimos el bien, agregando que las leyes universales corresponden a conocimientos de la razón práctica que aplicamos a los actos mediante juicios de conciencia(4). Esto se complementa con la idea de Santo Tomás de Aquino, quien señala que la conciencia indica la relación de un conocimiento con una cosa (I Q.79 a.13)(5).

Por otra parte, si bien la razón sustenta la con- ciencia y la intuición no es la base para la toma de decisiones, hay ciertos elementos que aparecen en forma natural y que difícilmente podrían ser argumentados sobre la base de otro conocimiento o razón, por ejemplo: "se debe hacer el bien y evitar el mal”. A esta capacidad de percibir los principios morales más básicos se le denomina synderesis(2), que, de acuerdo con Santo Tomás de Aquino, es el primer hábito natural (I Q.79 a.13) (5) y solo en este nivel la intuición cumpliría algún $\operatorname{rol}(2)$.

Según Sulmasy(2): "La conciencia surge de un compromiso (commitment) fundamental o intención de ser moral. Unifica los aspectos cognitivos, conativos y emocionales de la vida moral (...) Es un compromiso de sostener las creencias más profundas que nos identifican (...), de discernir los caracteres morales de los casos particulares en la mejor forma que podamos y de razonar moralmente al máximo de nuestras habilidades, un compromiso de balance emocional en la toma de decisiones (...) de decidir de acuerdo con la mejor habilidad moral que tenemos y actuar de acuerdo con lo que uno determinó como el curso de acción moralmente correcto".

Comprende así los distintos elementos que componen la estructura de conciencia y establece su capacidad de discernir y tomar decisiones de acuerdo con ello. Todo lo anterior, entendiendo la naturaleza humana con limitaciones, ya que condiciona su desarrollo a la habilidad. Engloba dentro de su visión no solo un teórico de razón, sino también de acciones concordantes, desprendiéndose que el actuar de la persona debe estar rectamente guiado por la conciencia y sus juicios. Propone luego que actuar conscientemente o acorde a nuestras más profundas creencias de la moralidad es uno de esos preceptos que vienen por synderesis. Sin embargo, actuar siempre en forma consciente no es fácil(2) y nos puede exponer a situaciones de conflicto con nuestros pares, la ley o con instituciones, como veremos.

\section{La formación de la conciencia, su adecuación con la verdad universal y la posibilidad de errar}

Como hemos visto, la conciencia tiene aspectos cognitivos que pueden ser sujetos de educación. Para su adecuada formación se requiere de fuentes 
externas, como la comunidad. En el catolicismo, la razón constituye un elemento central para la conciencia, produciéndose un complemento entre fe y razón. Dentro del laicismo, la razón es vista como la principal influencia de la concien$\operatorname{cia}(6)$.

En todos estos conceptos está patente la idea de que la conciencia no viene "prefabricada y lista para usar”, como sí podría haberse pensado en el concepto subjetivo de conciencia. De esta manera comprendemos que trae aparejada la obligación de formarla correctamente $(2,4)$. Hacerlo adecuadamente tiene relevancia, puesto que nos sirve como medida de protección ante un juicio moral erróneo al que todos estamos expuestos(7).

En Sulmasy, la conciencia está sujeta a las habilidades humanas: puede errar en sus juicios y no es siempre una guía moral infalible(2). Este aspecto también es destacado en la Encíclica Veritatis Splendor. Se entiende así la relevancia de tener razones fundadas, objetivas y explicables a otros, y que, por lo tanto, puedan ser evaluadas mediante criterios externos.

La existencia de criterios externos a la propia conciencia nos permite aclarar cuando la conciencia es correcta. Uno de estos criterios externos sería la adecuación de nuestro juicio de conciencia con la verdad universal. En este sentido, Juan Pablo II señala que la conciencia debe aspirar al seguimiento de una "verdad universal sobre el bien, que la razón humana puede conocer" (4), no siendo adecuado fijar el bien y el mal en forma autónoma y subjetiva, lo que llevaría a que cada uno encontrara una propia verdad. Este individualismo en su extremo llevaría a negar la naturaleza humana(4). No se busca de esta manera mermar la libertad individual. Todo lo contrario, la libertad se refuerza, pero entendiéndola siempre como dependiente de la verdad(4).

Siguiendo en la línea de los criterios externos, se plantea que las acciones no serían buenas o malas simplemente porque la conciencia lo dicte así, sino por su adecuación con la ley natural(3), la que corresponde a la participación de la ley eterna en la criatura racional (I-II, Q.91 a.2)(5), constituyendo así un orden de toda la naturaleza humana, especialmente la inteligencia y la volun- tad, hacia sus propios fines(8). La ley eterna es el plan por el cual la sabiduría de Dios ordena y dirige todos los actos y está entonces plasmada en cada ser en la ley moral natural. De este modo, los fundamentos del orden moral natural están en la inteligencia y el corazón de todo hombre y los podemos conocer. Gracias a esto, tenemos una tendencia natural a valorar los bienes y a estimar la conveniencia de los actos(8). A su vez, el juicio de conciencia no es autónomo, sino que opera a partir de la ley moral, pudiéndose entonces calificar como conciencia recta o errónea según su conformidad con la esta ley(8).

En el caso de la medicina, también se han fijado criterios externos a la propia conciencia. Se ha propuesto que las apelaciones de conciencia deben corresponderse con al menos un objetivo o valor de la medicina, como por ejemplo el alivio del sufrimiento. De esta forma se evitaría que se obligue a profesionales a involucrarse en prácticas condenadas por la profesión(9).

Vemos entonces que la conciencia no es infalible, por lo que exige una adecuada formación. Para evaluar su rectitud podemos utilizar los argumentos que la fundamenten y su adecuación con criterios externos.

\section{La libertad de conciencia como un derecho}

La Declaración Universal de los Derechos $\mathrm{Hu}-$ manos, en su artículo 18, sostiene: "Toda persona tiene derecho a la libertad de pensamiento, de conciencia y de religión...”. Luego, en el artículo 29, señala: "En el ejercicio de sus derechos y en el disfrute de sus libertades, toda persona estará solamente sujeta a las limitaciones establecidas por la ley, con el único fin de asegurar el reconocimiento y el respeto de los derechos y libertades de los demás, y de satisfacer las justas exigencias de la moral, del orden público y del bienestar general en una sociedad democrática" (10). Es decir, se asegura el derecho a la libertad de conciencia, pero también se menciona que este derecho está limitado por la ley, explicitando la razón de esta limitación. Por lo tanto, en caso de que la ley contraviniera la moral y el bienestar general, y de esta manera dejara de cumplir el objetivo para el cual se establece el límite a la libertad de conciencia, es inevitable plantearse que prevalecería 
la conciencia por sobre la ley.

Por su parte, los Principios de Siracusa(11) incluyen dentro de los derechos que no pueden ser suspendidos "...el derecho a la libertad de pensamiento, de conciencia y de religión. Estos derechos no admiten derogación en ninguna condición...”.

La Constitución Política de la República de Chile asegura a todas las personas, en su capítulo III, artículo 6: "La libertad de conciencia, la manifestación de todas las creencias y el ejercicio libre de todos los cultos que no se opongan a la moral, a las buenas costumbres o al orden público"(12).

Vemos así que la libertad de conciencia está contenida como un derecho, tanto nacional como internacionalmente, y se hace mención a ella en forma independiente de la libertad de culto. Sin embargo, ni los Principios de Siracusa ni los Derechos Humanos (así como tampoco la Constitución Política de Chile) definen qué se debe entender por "libertad de conciencia", pareciendo que esta falta de descripción fue ideada para incluir y proteger las distintas formas de entender el concepto(13).

\section{Ampliando la aplicación de los juicios de con- ciencia}

En la práctica clínica habitual son múltiples las situaciones en las que el clínico se enfrenta a conflictos que deben ser resueltos mediante un juicio de conciencia. Por ejemplo, ante un paciente que solicita un examen o interconsulta innecesarios o la extensión de una licencia, lo que es muy frecuente. Pareciera más fácil para el tratante ceder ante la solicitud del paciente; pero si lo hace está haciendo mal uso de recursos tanto económicos como técnicos y profesionales, perjudicando así el principio de justicia de los pacientes, lo que en conciencia es incorrecto. Más allá de la protección de los recursos y criterios técnicos, el juicio de conciencia nos señala que, aun en la situación teórica de que no existieran estas limitantes ni se perjudicara a otro, sería incorrecto en conciencia ceder ante estas solicitudes porque estaríamos faltando a la verdad.
Los conflictos éticos que enfrentamos a diario en nuestra práctica médica nos motivan a realizar juicios muchas veces pasados por alto, dado que en la relación médico-paciente todas las acciones deberían ser realizadas conscientemente(14). Estos ejemplos corresponden a disyuntivas a los que nos enfrentamos más frecuentemente de lo que la literatura ha hecho parecer hasta ahora, si bien sin tanta repercusión mediática como los casos paradigmáticos en que se apela a razones de conciencia.

\section{La objeción de conciencia}

\section{Historia y concepto}

Se citan como ejemplos clásicos, ilustrativos de objeción de conciencia, a Sócrates, Antígona, los jóvenes macabeos y los primeros cristianos; sin embargo, el concepto de objeción de conciencia, como lo entendemos hoy, no se formula sino hasta la objeción al servicio militar y a la guerra(15).

En la actualidad, la objeción de conciencia ha sido definida como "el derecho subjetivo que tiene por objeto lograr la dispensa de un deber jurídico o la exención de responsabilidad cuando el incumplimiento de ese deber se ha consumado"(16) y se agrega luego en este mismo artículo: “...para la objeción de conciencia, los motivos deben ser exclusivamente éticos o morales, basados en la autonomía de la conciencia individual”.

Se ha definido también objeción de conciencia como "...una forma de disentimiento de carácter no violento, que se manifiesta en el rechazo individual, por motivos fundamentalmente de carácter ético y religioso, de la obediencia externa a una disposición legislativa. Con ella se quiere manifestar el consentimiento profundo a otra ley de mayor rango e ineludible que persigue la conciencia" (15).

Más allá de las diferentes acepciones que se puedan encontrar en la literatura, todas parecen compartir elementos comunes:

- La existencia de una ley o disposición administrativa. 
- Que ese mandato sea contrario a lo que dicta la conciencia.

- Que en virtud de lo expuesto, la persona esté dispuesta a actuar acorde a su conciencia.

Para algunos autores, mostrarse contrario al mandato significa necesariamente una eventual consecuencia negativa; para otros, la expectativa de quedar exento de responsabilidad(16).

Si bien no está contenido en la mayoría de las definiciones, para aducir "objeción de conciencia" ante la ley la objeción debe estar contenida en el Derecho como una posibilidad. En Chile la ley no contempla actualmente el reconocimiento de la objeción de conciencia para el profesional de salud, al menos no en forma explícita.

Actualmente, no es infrecuente que en algunos países esté garantizado legalmente el derecho de objeción de conciencia, caso en el cual se deja de estar contra la ley(17) y, por lo tanto, se el objetor se exime de sufrir una sanción (o esta se desplaza).

Para efectos de este artículo, nos referiremos a "objeción de conciencia" en aquellas situaciones en que la ley positiva o una disposición administrativa se oponen al juicio de conciencia, independientemente de la eventual sanción o posibilidad de aducir a ella legalmente.

\section{¿Por qué respetar la objeción de conciencia?}

Como veíamos, la libertad de conciencia es un derecho ampliamente reconocido, independiente del concepto que se aplique. Parece lógica la posibilidad de actuar en concordancia y, de esta manera, la objeción de conciencia surge como un derecho humano básico(13). Lo anterior no siempre se entiende como tal y se podría argumentar que la libertad de conciencia no necesariamente implica el derecho a objeción de conciencia. Por este motivo, es necesario exponer otras razones que justifiquen el reconocimiento a esta última.

Se puede argumentar en favor de la objeción de conciencia por el respeto a la autonomía del objetor, ya que, al no permitírsele a alguien actuar en conciencia, se está mermando su autonomía y libertad. Sin embargo, como bien lo plantea Wicclair, referirse a la autonomía para justificar el derecho a objetar en conciencia tiene varios problemas. En primer lugar, sería argumentar muy ampliamente, puesto que se podrían justificar acciones que no fueran realmente en conciencia, amparadas bajo la autonomía; además, se podría respetar la objeción de conciencia aun sin respetar la autonomía de quien objeta, y respetar la autonomía no implica necesariamente que sus elecciones y acciones sean éticamente aceptables(9).

Existiría, no obstante, otra razón para objetar en conciencia. También de acuerdo con Wicclair(9), la razón de fondo para permitir la objeción de conciencia es el respeto a la integridad moral. Señala el autor que la integridad moral implica tener valores que forman parte de la propia identidad y que serían incompatibles con el acto que se objeta. Iría más allá incluso de juzgar un acto como ético o no, puesto que faltar a esos valores que forman parte de la visión que la persona tiene sobre sí misma correspondería a una pérdida del respeto por sí mismo.

La posibilidad de que la conciencia se oponga a la ley humana positiva también se encuentra en las reflexiones de Santo Tomás (I-II Q.95 a.2)(5), quien señala que la ley positiva solo tiene fuerza si deriva de la ley natural. Si está en desacuerdo con ella, la ley positiva deja de ser ley y se convierte en corrupción de la ley. Este aspecto fundamental se destaca en una de las definiciones de objeción de conciencia planteadas previamente: "Con ella se quiere manifestar el consentimiento profundo a otra ley de mayor rango e ineludible que persigue la conciencia”.

\section{Conflicto entre la objeción de conciencia y la responsabilidad profesional}

En la literatura se plantea que el médico objetor está negando el derecho a salud de los pacientes y su autonomía(18), contraponiéndose de esta manera con su responsabilidad profesional. Se ha afirmado incluso que un médico objetor no debería ser médico o que solo sería permisible la objeción de conciencia mientras existan otros médicos dispuestos a proveer el servicio en cuestión(19). También se ha señalado que los médicos objetores deberían confinarse a instituciones de salud que respalden su actuar o a especialidades donde no se expongan a situaciones clínicas que objetar(18). 
Baker señala que el profesional objetor debe garantizar una alternativa y, si la derivación no es una opción, debería realizar el servicio que se le solicite independiente de su objeción. En caso de que así no actúe, constituiría una conducta antiprofesional.

La autonomía del paciente merece respeto, sin lugar a dudas, pero no por eso se puede mermar a su vez la autonomía e integridad del profesional. El médico y su paciente son personas y ambos también agentes morales(14). No por ejercer su rol, el profesional de salud se puede desligar de la responsabilidad de sus actos amparado bajo "la obligación profesional”, ya que todas sus acciones están sujetas a su juicio de conciencia y actuar en concordancia es una obligación moral.

No se puede reducir al profesional de salud a un mero prestador de servicios sin capacidad de emitir juicios, o limitarlo solo a actuar conscientemente bajo ciertas condiciones, obligándolo a actuar en otras contra su conciencia; hacerlo dañaría su dignidad(20).

La responsabilidad de un profesional no se ve mermada por actuar en conciencia, sino absolutamente lo contrario: es la conciencia lo que permite y obliga a ser responsable. Aludiendo a cómo la conciencia está presente en cada uno de los actos del médico se ha señalado: "quiten mi conciencia mientras mantienen mi posibilidad de ejercer y pronto estaré en la cárcel, con justa razón” (14), evidenciando también cómo el buen actuar del médico depende de su conciencia.

\section{Relación médico-paciente y la derivación. ¿La solución?}

Si bien la objeción de conciencia se puede dar en el nivel médico-Estado o médico-institución de salud, es en la relación médico-paciente en la que se produce el conflicto moral más profundo. Es ahí donde se enfrentan, eventualmente, la autonomía del médico con la del paciente(3).

En principio, la actitud del objetor debería ser argumentar su posición al paciente. Si bien la conciencia debería ser respetada por sí misma, presentar los argumentos al paciente evita que erróneamente éste piense que se le niega algo en forma antojadiza. Es además posible que, a la luz de los argumentos, el paciente decida cambiar de opinión; si bien la finalidad de la objeción de conciencia no es por sí misma cambiar la conducta de los otros o la opinión pública(3), podría eventualmente traer esto aparejado, al educar la conciencia del paciente, por ejemplo si se le expone la evidencia disponible. Tampoco es adecuado abandonar al paciente. Se le debe manifestar que no se puede cumplir con lo que éste solicita y ofrecer alternativas que no parezcan objetables y que resuelvan su problema, así como también ofrecer seguir formando parte de su cuidado.

Una vez hecho lo anterior, es posible que el paciente siga buscando acceder de alguna forma al acto que nos parece objetable. En aquellos lugares donde se respeta legalmente a los objetores de conciencia, se propone frecuentemente como solución que el paciente sea derivado a un profesional que no sea objetor. Se ha señalado que esto balancearía los derechos del paciente y del profesional sanitario con objeción de conciencia(17). Sin embargo, pareciera que, al derivar un paciente y por tanto participar en que otro realice lo que nos parece objetable, nos haría en cierta medida también partícipes de ese acto, puesto que seguiríamos formando parte de la cadena causal(17). Si bien es cierto que no somos responsables de los actos de otras personas, si derivamos actuamos en forma indirecta para que se realice lo que consideramos incorrecto. Aun si se planteara la derivación como solución, tampoco se resuelve el problema para el paciente, ya que pacientes con menos recursos o de zonas rurales tendrían menos acceso(17), o algunos podrían no querer una derivación, preocupados por ejemplo por la calidad de atención que recibirían(9).

Una manera de respetar la integridad del médico sin afectar los derechos del paciente sería informar a este con antelación los valores que restringirán los servicios que se proveerán; sin embargo, esto podría estar en cierta forma limitado por la dificultad de anticiparse a todas las situaciones potencialmente generadoras de objeción de conciencia(9).

El ejemplo de la derivación nos enfrenta a lo que se ha denominado "complicidad moral", que 
comprende todas aquellas circunstancias en las que colaboramos en algún grado de un acto que nos parece incorrecto en conciencia. Definir el límite en el cual pasamos a tener responsabilidad no es fácil y se han planteado ciertos elementos que nos ayudarían a establecer el grado de complicidad moral, dentro de los cuales el más importante es compartir el propósito, ya que esto nos haría igualmente responsables, aun si nuestra colaboración no fuera como autores materiales $(2,21)$.

\section{Algunos aspectos prácticos sobre la aplicación de la objeción de conciencia del profesional sa- nitario en Chile}

Muchos de los actos sujetos a objeción de conciencia son permitidos por la ley, pero la permisión no necesariamente da el derecho de obligar a otra persona a que haga lo permitido(22). Sin embargo, existen circunstancias en las cuales la ley garantiza un derecho, como en el caso de aquella que fija normas sobre información, orientación y prestaciones en materia de regulación de la fertilidad(23) y que señala en su artículo 1: "Toda persona tiene derecho a recibir educación, información y orientación en materia de regulación de la fertilidad, en forma clara, comprensible, completa (...) Dicha educación e información deberán entregarse por cualquier medio, de manera completa y sin sesgo, y abarcar todas las alternativas que cuenten con la debida autorización...", para luego agregar en el artículo 2: "Toda persona tiene derecho a elegir libremente, sin coacción de ninguna clase y de acuerdo a sus creencias o formación, los métodos de regulación de la fertilidad femenina y masculina que cuenten con la debida autorización y, del mismo modo, acceder efectivamente a ellos...".

Tanto la llamada anticoncepción de emergencia como el dispositivo intrauterino han sido cuestionados por su eventual mecanismo abortivo, razón por la cual hay profesionales de la salud que objetan su administración. También, existen profesionales de la salud que cuestionan alguno de estos métodos, dado que consideran que no existe evidencia disponible para descartar absolutamente su carácter abortivo, lo cual impediría concluir el juicio de conciencia generando de este modo la conciencia dudosa, que indica que hay que abste- nerse de actuar hasta una vez resuelta la duda(8). Asimismo, hay profesionales de la salud que objetan el uso de cualquier método anticonceptivo artificial.

En el caso de un profesional sanitario ejerciendo en el sistema público de salud, cuyo paciente puede no tener libertad de elección, queda atado a la disposición legal y se ve en la obligación, sin capacidad de objeción aceptada por la ley, de proveer los métodos que el paciente elija. Que la ley no contemple la posibilidad de objetar parece algo inapropiado, ya que, en el propósito de respetar la libertad y autonomía del paciente se vulnera a su vez la posibilidad de que el profesional actúe en concordancia con su libertad de conciencia, su autonomía y su integridad moral.

Existen otras situaciones en Chile en las que el profesional de salud concluye que la forma de actuar en conciencia se contradice con lo que exige la ley. Particularmente en el caso de pacientes con diagnóstico de portación de Virus de Inmunodeficiencia Humana (VIH) y SIDA. Existe en el país normativa legal explícita contenida en el reglamento del examen para la detección del virus que señala en su artículo 2: “...todo el personal de salud, tanto profesional como auxiliar que, a raíz del desarrollo de su trabajo, intervenga o tome conocimiento de la realización de un examen de este tipo deberá mantener la más estricta confidencialidad sobre la persona involucrada, los resultados del mismo y toda circunstancia relacionada con dicho procedimiento..."(24).

Se resguarda con este artículo la confidencialidad de los pacientes portadores de VIH, lo que no es menor en el caso de una enfermedad infectocontagiosa, puesto que la confidencialidad se puede contraponer a bienes que el médico debería proteger, como la salud pública. Los pacientes portadores del VIH son educados inicialmente en la necesidad de proteger a los contactos y la importancia de darles la oportunidad de diagnóstico y eventual tratamiento, pero si el paciente decide no comunicarle esto a sus contactos la prohibición de informar también le impide realizar esto al profesional de salud. De esta manera, la única forma de actuar acorde con lo que dicta la conciencia y evitar la eventual sanción legal es judicializando los casos para proteger la salud de 
los contactos, pudiendo aducirse en este caso no únicamente razones de conciencia sino de protección a terceros. Esto debería ser incluido en la ley nacional, como lo hacen otros países, entendiendo que el paciente portador de VIH es no solo un paciente con derechos sino también con deberes(25). Se discute que vulnerar la confidencialidad de estos pacientes podría tener además repercusión negativa, dado que podría generar temor en ellos(25), por lo que la resolución de estos casos no es en ningún caso simple. De aprobarse en Chile el proyecto de ley que regula los derechos y deberes que las personas tienen en relación con acciones vinculadas a su atención en salud, este aspecto podría ser contemplado, ya que seńala el derecho a que la información del estado de salud no pueda ser revelada a terceros con tres excepciones, siendo las dos primeras atingentes a este asunto: “... en primer lugar, que razones de salud pública justifiquen que esa información sea entregada a terceros. En segundo lugar, que la falta de información suponga un grave riesgo para la salud de terceros identificables..." (26).

Otro aspecto interesante es cuando el paciente manifiesta razones de conciencia ante su médico. Por ejemplo, pacientes Testigos de Jehová que objetan ser sometidos a transfusiones sanguíneas, aunque estos casos no se correspondan estrictamente con la definición de objeción de conciencia, porque un paciente adulto competente no tiene la obligación legal de someterse a este procedimiento. Este es un tema sujeto a discusión, puesto que se trata de un paciente argumentando en relación con sus creencias e interpretación de las escrituras, lo que podría generar conflicto con su tratante que objeta en conciencia su deber de defender la vida. Por un lado, la vida prima por sobre otros valores pero, por otra, los Testigos de Jehová esgrimen que al trasgredir lo que se señala en las escrituras(27) se vulneraría el derecho a la vida eterna(28) y, además, experimentarían un deterioro en su calidad de vida terrenal sabiendo que fueron sometidos a una transfusión y al eventual juicio de su comunidad. De este modo, se ha planteado que el procedimiento podría ser considerado desproporcionado en vista de los efectos negativos que provoca en el paciente(28).
En caso de que se decida respetar el juicio de conciencia del paciente, es importante asegurarse de que su decisión sea válida: esta debe ser personal, sin influencia de otros y el paciente debería ser capaz de argumentarla; sin embargo, en este caso parece bastante complejo establecer su adecuación con criterios externos más allá de los de su propia comunidad.

\section{Conclusión}

Si bien existe mucha discusión en la actualidad respecto del concepto de conciencia moral, parece haber consenso en uno de sus elementos fundamentales: su base racional y la existencia de elementos externos que permiten evaluar su corrección.

La conciencia y sus juicios estarían presentes en cada uno de los actos del ser humano, incluyendo las acciones cotidianas del profesional de salud. La posibilidad de actuar en concordancia corresponde a una obligación y a un precepto básicos para las personas.

Así como la ley se ha preocupado de los derechos de los pacientes, es relevante que también se tomen en consideración los derechos de los profesionales de la salud. Es imperioso que se considere la posibilidad de objeción de conciencia en forma explícita, siempre que sea fundamentada, de manera de respetar también la integridad moral del profesional.

\section{Agradecimientos}

A Mariano Crespo, por su gran colaboración y guía en aspectos filosóficos relativos al tema. Por compartir su experiencia en relación a juicios de conciencia en distintos campos de la atención en salud, a Solange Rivera, Rodrigo González, Brenda Mesías, Sonia Barreda, Claudia Carvajal, Francisca Valdivieso, Macarena Lizama y Jorge Neira. Por su orientación en aspectos jurídicos, a Ângela Vivanco. 


\section{Referencias}

1. Emerson C, Daar A. Defining conscience and acting conscientiously. American Journal of Bioethics 2007; 7(12): 19-21.

2. Sulmasy DP. What is conscience and why is respect for it so important? Theor Med Bioeth 2008, 29: 135-149.

3. Manuell G, Sotelo G, Casa O. La objeción de conciencia en la práctica del médico. Rev Fac Med UNAM 2006, 49(3): 121-125.

4. Juan Pablo II. Encíclica "Veritatis Splendor". 6 de Agosto de 1993. Disponible en http://www.vatican.va/ holy_father/john_paul_ii/encyclicals/documents/hf_jp-ii_enc_06081993_veritatis-splendor_sp.html Último acceso el 16 de septiembre de 2010.

5. Santo Tomás de Aquino. Suma de Teología. 2a ed. Madrid: Biblioteca de Autores Cristianos; 2009.

6. Lawrence RE, Curlin FA. Clash of definitions: Controversies about conscience in medicine. American Journal of Bioethics 2007; 7(12): 10-14.

7. Hardt J. The conscience debate: resources for rapprochement from the problem's perceived source. Theor Med Bioeth 2008; 29: 151-160.

8. Rodriguez A. El orden moral. En Ética. $1^{\text {a }}$ ed. Tercera reimpresión. Pamplona: Ediciones Universidad de Navarra; 1982: 81-105.

9. Wicclair M. Conscientious objection in medicine. Bioethics 2000; 14(3): 205-227.

10. United Nations. Universal declaration of human rights. Versión en español disponible en http://www.ohchr. org/EN/UDHR/Pages/Language.aspx?LangID =spn.

11. United Nations. United Nations Economic and Social Council. U.N. Sub Comission on Prevention of Discrimination and Protection of Minorities. Siracusa (1984) Principles on the limitation and derogation of provisions in the International Covenant on Civil and Political Rights. Disponible en http://hei.unige.ch/-clapham/hrdoc/ docs/siracusa.html.

12. Chile. Constitución Politica de la República de Chile. $8^{\circ}$ ed. Actualizada el 25 de enero de 2008. Santiago de Chile: Lexis Nexis; 2008.

13. Sutton EJ, Ross EG. Are there different spheres of conscience? J Eval Clin Pract 2010; 16(2): 338-343.

14. Barfield R. Conscience is the means by which we engage the moral dimension of medicine. American Journal of Bioethics 2007; 7(12): 26-27.

15. Gutiérrez JG. La objeción de conciencia de los profesionales de salud. México: Asociación mexicana de promoción cultural y social AC; 2001.

16. León Correa FJ. Fundamentos ético jurídicos de la objeción de conciencia de los profesionales de la salud. Revista CONAMed 2007; 12(1): 3-8.

17. Card RF. Conscientious objection and emergency contraception. American Journal of Bioethics 2007; 7(6): 8-14.

18. Baker R. Conscience and the unconscionable. Bioethics 2009; 23(5): 2-4.

19. Savulescu J. Conscientious objection in medicine. BMJ 2006; 332: 294-297.

20. Spaemann R. El individuo o ¿̧hay que seguir siempre la conciencia?. En Ética: cuestiones fundamentales. 6a ed., España: Ediciones Universidad de Navarra; 2001: 85-97.

21. Orr R. The role of moral complicity in issues of conscience. American Journal of Bioethics 2007; 7(12): 23-24.

22. Hill DJ. Abortion and conscientious objection. J Eval Clin Pract 2010; 16(2): 344-350.

23. Chile. Ministerio de Salud. Ley 20418. Fija normas sobre información, orientación y prestaciones en materia de regulación de la fertilidad. Santiago de Chile, 2 de febrero de 2010.

24. Chile. Ministerio de Salud. Decreto 182. Reglamento del examen para la detección del virus de la inmunodeficiencia humana. Santiago de Chile, 9 de enero de 2007.

25. Ocampo J. Bioética y VIH/SIDA: La responsabilidad del paciente, la sociedad y el estado. An Med Asoc Med Hosp $A B C$ 2005; 50(3): 136-140.

26. Chile. Mensaje de S.E. la Presidenta de la República con el que inicia un proyecto de ley que regula los 
derechos y deberes que las personas tienen en relación con acciones vinculadas a su atención en salud. Mensaje Presidencial $\mathrm{N}^{\circ}$ 223-354. Santiago de Chile, 26 de julio de 2006.

27. Jehova's Witnesses Official Media Weeb Site. Why don't you accept blood transfusions? Disponible en: http:// www.jw-media.org/aboutjw/article01.htm\#accept Último acceso el 23 de septiembre de 2010.

28. Besio M, Besio F. Testigos de Jehová y transfusión sanguínea. Reflexión desde una ética natural. Rev Chil Obstet Ginecol 2006; 71(4): 274-279.

Recibido: 14 de febrero de 2011

Aceptado: 22 de abril de 2011 